\title{
Strategi Pengembangan Desa Wisata Timpag Berbasis Masyarakat di Kecamatan Kerambitan, Kabupaten Tabanan Bali
}

Gusti Ayu Putu Marwangi a,1 I Putu Anom a,2

1putumarwangi482@gmail.com 2putuanom@unud.ac.id

a Program Studi Sarjana Destinasi Pariwisata, Fakultas Pariwisata, Universitas Udayana, Jl. Dr. R. Goris, Denpasar, Bali 80232 Indonesia

\begin{abstract}
Tabanan Regency has a high prospect in the development of tourism and its complementary facilities. Tourism village is the alternative tourism products that can provide the development of rural areas that are certainly sustainable for the future. Timpag Village is one of the villages which located in Kerambitan District, Tabanan Regency which has several tourism potentials such as nature, cultures, and the local communities. The development of Rural Tourism in Timpag Village has a high value to be a tourist attraction but the reality this village has not been able to be a developed as a rural tourism. Based on these problems this research aims to determine "Development Strategies of Rural Tourism Based Local Community in Timpag Village, Kerambitan District, Tabanan Regency Bali."

The research method used in this study is a qualitative descriptive analysis supported by IFAS and EFAS analysis in designing a strategy for developing local community-based tourism villages used SWOT analysis. Data collection techniques are using the method of observation, interviews, library research.

The result show the design of alternative strategies to develop community-based tourism villages that can be applied in the development of Rural Tourism in Timpag Village. There are six altrenative strategys that can be applied such as attractions development based on tourism potential, local communities involvement, tourism facilities development, tourism organisation development, improve the traditional security system, and improve the ability of communities about tourism development. Therefore, local communities need to preserve the tourism potential that is owned as a rural tourism product.
\end{abstract}

Keywords: Rural Tourism, Community Based Tourism, and Strategy

\section{PENDAHULUAN}

Kabupaten Tabanan merupakan kabupaten yang terletak bagian selatan Pulau Bali. Batas wilayah Kabupaten Tabanan terbagi empat yaitu dengan Kabupaten Buleleng disebelah utara, Kabupaten Badung disebelah timur, Samudera Indonesia disebelah selatan dan Kabupaten Jembrana disebelah barat. Kabupaten Tabanan memiliki luas wilayah $839,33 \mathrm{~km}^{2}$ dengan persebaran potensi pariwisata yang ada dimasing-masing kecamatan sebagai faktor utama dalam pengembangan sektor pariwisata.

Kabupaten Tabanan mempunyai prospek yang sangat cerah dalam pengembangan pariwisata dan sarana pelengkapnya. Terbukti sampai saat ini pariwisata di Kabupaten Tabanan dapat dikatakan layak dan sangat baik. Hal ini dibuktikan dengan terus berkembangnya daerah tujuan wisata berupa desa wisata yang berbasis masyarakat (Kabar Berita Antara Bali, 2012).

Berdasarkan hal tersebut di atas para kepentingan pariwisata mulai menggali potensi yang dimiliki oleh daerahnya dan sebisa mungkin mengkemasnya menjadi produk pariwisata alternatif. Hal tersebut merupakan salah satu upaya positif yang baik dan juga untuk menjadikan pariwisata yang sifatnya berkelanjutan yang berarti bertahan dalam jangka waktu yang lebih lama. Mengingat bahwa adanya kesadaran wisatawan akan dampak yang terjadi akibat pariwisata massal membuat terjadinya perubahan minat dan tren pariwisata menuju pariwisata alternatif yang cenderung memperhatikan kualitas pariwisata pasa suatu daya tarik wisata.

Desa wisata adalah salah satu bentuk produk wisata alternatif dengan prinsip pembangunan desa wisata tentunya mengembangkan produk lokal pedesaan juga mengarah pada manfaat yang nantinya berdampak langsung kepada masyarakat setempat. Pengembangan desa wisata sebagai produk alternatif telah disandingkan dengan konsep pariwisata berbasis masyarakat. Pengembangan desa wisata berbasis masyarakat merupakan model pengembangan yang akan memberikan peluang yang besar kepada masyarakat lokal untuk ikut berpartisipasi pada kegiatan pariwisata. 
Kabupaten Tabanan memiliki 22 desa wisata yang telah menerima Surat Keputusan dari Bupati Tabanan. Beberapa desa wisata yang telah berkembang baik adalah desa wisata Jatiluwih, desa wisata Pinge, desa wisata Munduk Temu, desa wisata Belimbing, dan desa wisata Tista. Semakin tahun jumlah desa wisata di Kabupaten Tabanan semakin bertambah hal tersebut dikarenakan antusias masyarakat untuk mengembangkan desanya menjadi desa wisata (Kabar Berita Bisnis Bali, 2018). Seperti halnya masyarakat yang berada di Desa Timpag yang saat ini sangat antusias ingin mengembangkan Desa Timpag menjadi desa wisata namun masyarakat belum memanfaatkan secara optimal potensi wisata yang dimiliki Desa Timpag.

Desa Timpag merupakan salah satu desa yang terletak di Kecamatan Kerambitan Kabupaten Tabanan yang memiliki beberapa potensi wisata alam, potensi wisata budaya dan buatan yang sangat baik untuk dikembangkan. Hal tersebutlah yang mendasari dan menjadi pertimbangan masyarakat di Desa Timpag berinisiatif ingin mengembangkan potensi wisata desanya sehingga mendukung pengembangan desa wisata. Untuk memanfatkan dan memaksimalkan potensi wisata yang dimiliki maka dirasa perlu menciptakan suatu rumusan strategi pengembangan desa wisata Timpag yang berbasis masyarakat agar berkelanjutan.

Dengan demikian, penelitian ini menjadi penting dilakukan untuk merumuskan strategi pengembangan desa wisata berbasis masyarakat di Desa Timpag.

\section{TINJAUAN PUSTAKA}

\subsection{Telaah Penelitian Sebelumnya}

Penelitian kepariwisataan mengenai potensi wisata dalam pengembangan desa wisata telah dilakukan beberapa peneliti. Penelitian ini dilakukan dengan mengacu terhadap jurnal penelitian yang telah dipublikasikan. Adapun telaah hasil penelitian sebelumnya terkait dengan fokus penelitian diantaranya sebagai berikut.

Penelitian Pertama yaitu Jurnal Analisis Pariwisata dengan judul "Model Strategi Pengembangan Desa Wisata Berbasis Masyarakat di Desa Kenderan, Gianyar, Bali" oleh Ni Putu Eka Mahadewi dan I Putu Sudana (2017). Penelitian tersebut dilakukan di Desa Kenderen Kabupaten Gianyar Provinsi Bali. Hasil dari penelitian tersebut adalah pengembangan pariwisata pedesaan di Desa Kenderan ditinjau dari aspek destinasi, aspek industri, aspek pemasaran dan aspek kelembagaan. Berdasarkan hal tersebut perlu dirancang strategi dalam pengembangan pariwisata pedesaan di Desa Kenderan berbasis masyarakat. Adapun strategi yang telah dirancang adalah strategi pengembangan dalam aspek destinasi pariwisata, strategi pengembangan dalam aspek industri pariwisata, strategi pengembangan dalam aspek pemasaran pariwisata dan strategi pengembangan dalam aspek kelembagaan pariwisata.

Penelitian Kedua adalah Jurnal Master Pariwisata dengan judul "Strategi Pengembangan Pariwisata Berbasis Masyarakat di Desa Kemetul Kabupaten Semarang" oleh Rindo Bagus Sanjaya (2018). Hasil dari penelitian ini adalah Desa Kemetul memiliki potensi pariwisata dengan didukung adanya akses dan fasilitas yang memadai serta dukungan masyarakat lokal. Dalam meningkatkan pengembangan Adanya dukungan masyarakat lokal Desa Kemetul terhadap perencanaan dan pengembangan desa wisata sudah sejalan dengan prinsip pariwisata berbasis masyarakat. Adapun strategi pengembangan yang dirancang menggunakan pendekatan SWOT dengan hasil adalah strategi pengembangan kelembagaan dan SDM, strategi promosi, strategi penguatan produk unggulan, strategi pengembangan daya tarik wisata berkelanjutan.

Penelitian Ketiga adalah jurnal dengan judul "Pelatihan Manajemen Kelembagaan Desa Sebagai Upaya Pemberian Pelayanan Prima Kepada Masyarakat dan Pengelolaan Potensi Desa di Desa Timpag Tabanan" oleh I Made Wimas Candranegara, I Dewa Gede Putra Sedana, dan Ketut Sri Swatiningsih (2018). Penelitian ini dilakukan di Desa Timpag Kecamatan Kerambitan Kabupaten Tabanan. Hasil dari penelitian tersebut adalah kelembagaan desa, aparatur desa dan masyarakat Desa Timpag telah memahami konsep manajemen kelembagaan desa dan garis besar kebijakan dalam tata aturan Pemerintah RI yang normatif. 


\subsection{Tinjauan Konsep}

Dalam penelitian ini menggunakan beberapa konsep untuk menganalisis permasalahan, yaitu konsep strategi (Chandler dalam Rangkuti, 2005), konsep pengembangan desa wisata (Pearce, 1995) dan konsep pariwisata berbasis masyarakat (Pearce, 2005).

\section{METODE}

Penelitian ini dilakukan di Desa Timpag, Kecamatan Kerambitan, Kabupaten Tabanan Provinsi Bali. Untuk menuju Desa Timpag hanya menempuh waktu kurang lebih 30 menit dari pusat Kota Tabanan. Desa Timpag memiliki 13 banjar adat.

Teknik pengumpulan data dalam penelitian ini yaitu menggunakan teknik observasi yaitu peneliti terjun langsung ke lokasi penelitian untuk mengamati potensi wisata di Desa Timpag. Kemudian peneliti juga melakukan wawancara dengan Kepala Desa dan Masyarakat mengenai kekuatan, kelemahan, peluang dan ancaman yang ada di Desa Timpag.

Sumber data yang digunakan dalam penelitian ini yaitu sumber data primer dan data sekunder. Sumber data primer antara lain potensi wisata yang ada di Desa Timpag dan identifikasi kekuatan, kelemahan, peluang dan ancaman di Desa Timpag. Data sekunder antara lain mengenai letak geografis Desa Timpag.

Teknik analisis data yang digunakan adalah teknik analisis SWOT yaitu suatu langkah untuk mengidentifikasi segala faktor dalam rangka merancang strategi yang akan disajikan secara deskriptif kualitatif.

\section{HASIL DAN PEMBAHASAN \\ Potensi Desa Timpag sebagai Desa Wisata}

Desa Timpag memiliki potensi pariwisata yang cukup besar untuk dikembangkan sebagai suatu wisata perdesaan ditinjau dari potensi alam, potensi budaya, dan potensi buatan. Adapun potensi wisata Desa Timpag seperti: potensi alam berupa pemandangan dan hamparan persawahan dengan luas 375 hektar yang menghijau dengan suasana perdesaan dan aktivitas bertani di sawah, sungai, dan konservasi jenis burung hantu seperti Burung Hantu Tyto Alba.

Potensi budaya seperti Pura Desa-PusehDalem Tradisi Nangkluk Merana, Pura Beji dengan pancoran tempat pembersihan diri (melukat). Potensi buatan seperti Bendungan Telaga Tunjung sebagai tempat penampungan irigasi dan menawarkan pemandangan yang sungguh menarik.

\section{Analisis SWOT Pengembangan Desa Wisata di Desa Timpag.}

Berdasarkan potensi wisata yang dimiliki oleh Desa Timpag, maka dilakukan analisis SWOT untuk menemukan strategi yang tepat untuk diterapkan. Pada Tabel 1. akan dirumuskan strategi pengembangan desa wisata di Desa Timpag. 
Tabel 1.

Matrkis SWOT Strategi Pengembangan Desa Wisata di Desa Timpag

\begin{tabular}{|c|c|c|}
\hline & Kekuatan (Strength) & Kelemahan (Weakness) \\
\hline Faktor Eksternal & $\begin{array}{l}\text { 1. Suasana persawahan di } \\
\text { Desa Timpag sangat asri. } \\
\text { 2. Desa Timpag memiliki } \\
\text { potensi wisata alam berupa } \\
\text { bentangan persawahan } \\
\text { yang asri dan konservasi } \\
\text { burung hantu Tyto Alba. } \\
\text { 3. Adanya dukungan dari Desa } \\
\text { Adat dan Dinas Pariwisata. } \\
\text { 4. Adanya keinginan } \\
\text { masyarakat yang tinggi } \\
\text { untuk ikut berpartisipasi } \\
\text { dalam pengembangan desa } \\
\text { wisata. } \\
\text { 5kseisbilitas yang baik dan } \\
\text { mudah untuk dilalui. } \\
\text { 6. Jalan Raya Timpag } \\
\text { merupakan jalur ramai } \\
\text { dilalui menuju daya tarik } \\
\text { wisata lain. }\end{array}$ & $\begin{array}{ll}\text { 1. Kurang tertatanya kondisi } \\
\text { lingkungan. } \\
\text { 2. Latar pendidikan } \\
\text { masyarakat cenderung } \\
\text { lemah dibidang pariwisata } \\
\text { khususnya tentang konsep } \\
\text { desa wisata. }\end{array}$ \\
\hline
\end{tabular}




\begin{tabular}{|c|c|c|c|}
\hline & Peluang (Opportunities) & Strategi So & Strategi WO \\
\hline 4. & $\begin{array}{l}\text { Adanya Kebijakan } \\
\text { Pemerintah Kabupaten } \\
\text { Tabanan mengenai } \\
\text { Pengembangan Desa Wisata } \\
\text { di Kabupaten Tabanan. } \\
\text { Adanya Kebijakan } \\
\text { Pemerintah Provinsi dalam } \\
\text { meningkatkan jumlah } \\
\text { kunjungan wisatawan. } \\
\text { Perkembangan tren wisata } \\
\text { perdesaan (rural tourism). } \\
\text { Meningkatnya } \\
\text { perkembangan teknologi } \\
\text { informasi }\end{array}$ & 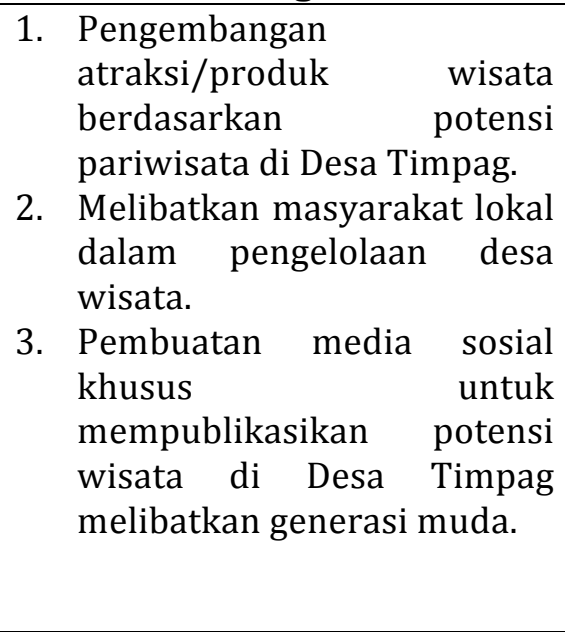 & $\begin{array}{l}\text { 1. Penataan fasilitas pariwisata } \\
\text { guna pemenuhan kebutuhan } \\
\text { wisatawan yang berkunjung. } \\
\text { 2. Membentuk suatu lembaga } \\
\text { masyarakat untuk } \\
\text { pengelolaan desa wisata. }\end{array}$ \\
\hline \multicolumn{2}{|r|}{ Ancaman (Treart) } & Strategi ST & Strategi WT \\
\hline & $\begin{array}{l}\text { Terjadi peningkatan } \\
\text { persaingan sumber daya } \\
\text { manusia dalam bidang } \\
\text { pariwisata } \\
\text { Adanya persaingan produk } \\
\text { wisata dengan desa wisata } \\
\text { lainnya. } \\
\text { Terdapat isu keamanan dan } \\
\text { kesehatan }\end{array}$ & $\begin{array}{ll}\text { 1. } & \text { Meningkatkan sistem } \\
\text { keamanan berbasis desa } \\
\text { adat. } \\
\text { 2. Menciptakan citra merek } \\
\text { Desa Timpag sebagai ikon } \\
\text { Desa Wisata. }\end{array}$ & $\begin{array}{l}\text { 1. Meningkatkan kemampuan } \\
\text { sumber daya manusia di } \\
\text { Desa Timpag dalam bidang } \\
\text { pariwisata meluli pembinaan } \\
\text { dan pelatihan. }\end{array}$ \\
\hline
\end{tabular}

Sumber: Hasil Analisis, 2018

\section{Penyesuaian Strategi Pengembangan Desa Wisata Timpag dengan Konsep Pariwisata Berbasis Masyarakat}

Arahan strategi pengembangan desa wisata berbasis masyarakat merupakan suatu upaya yang dilakukan untuk memanfaatkan potensi wisata yang dimiliki Desa Timpag menuju desa wisata dengan melibatkan masyarakat secara utuh. Adapun arahan perumusan strategi yang dapat diterapkan di Desa Timpag adalah sebagai berikut.

1. Strategi Strengths Opportunities (SO):

a. Pengembangan atraksi/produk wisata sesuai potensi pariwisata di Desa Timpag.

Hal tersebut dapat dilakukuan dengan memanfaatkan potensi wisata yang dimiliki Desa Timpag sebagai kegiatan wisata seperti misalnya aktivitas wisata alam dibuka jalur trekking bagi wisatawan untuk berkeliling persawahan dengan berinteraksi dengan masyarakat lokal lalu berfoto di spot foto selfie dan melihat penangkaran burung hantu tyto alba dengan melibatkan masyarakat sebagai pemandu wisata. b. Melibatkan masyarakat lokal dalam pengelolaan desa wisata.

Suatu desa wisata akan berjalan baik jika pengelolaannya melibatkan masyarakat lokal. Hal tersebut karena masyarakat merupakan aktor utama dalam kegiatan pariwisata di desanya sehingga keputusan terhadap pengembangan desa wisata tetap berada ditangan masyarakat lokal.

2. Strategi Weakness Treats (WT):

a. Penataan fasilitas pariwisata guna pemenuhan kebutuhan wisatawan yang berkunjung.

Penataan fasilitas pariwisata juga perlu dilakukan seperti penyediaan homestay / rumah masyarakat lokal, sehingga wisatawan dapat berinteraksi langsung dengan masyarakat, tempat makan yang menyediakan makanan khas Desa Timpag dengan melibatkan Ibu PKK Desa Timpag, dan pusat informasi wisata serta tersedianya oleh-oleh yang dapat menjadi ciri khas Desa Timpag agar selalu diingat wisatawan yang berkunjung. Hal tersebut agar masyarakat dapat menjaga 
ciri khas dan mendapatkan manfaat ekonomi secara berkelanjutan.

b. Membentuk suatu lembaga masyarakat untuk pengelolaan desa wisata.

Suatu desa wisata memerlukan kelembagaan mengingat bahwa kelembagaan merupakan salah satu komponen dalam penyelenggaran kegiatan pariwisata. Desa Timpag belum memiliki suatu lembaga yang khusus mengelola desa wisata. Pembentukan Kelompok Sadar Wisata atau Pokdarwis akan membantu dalam pengembangan pariwisata di Desa Timpag.

3. Strategi Strengths Treats (ST):

a. Meningkatkan sistem keamanan berbasis desa adat.

Meningkatkan sistem keamanan berbasis desa adat dalam kegiatan pariwisata adalah hal yang memang wajib untuk diimplementasikan dalam menjaga keamanan dan ketertiban kegiatan pariwisata. Setiap banjar di Desa Timpag telah memiliki petugas pecalang. Hal ini dimaksudkan untuk membentuk suatu citra desa wisata agar wisatawan merasa nyaman saat berkunjung ke Desa Timpag.

4. Strategi Weakness Treats (WT):

a. Peningkatan kemampuan sumber daya manusia di Desa Timpag dalam bidang pariwisata.

Hal tersebut dapat dilakukan dengan melakukan pertemuan rutin kepada masyarakat dalam pengenalan khususnya dalam bidang pariwisata seperti misalnya tentang pengenalan pariwisata, desa wisata yang dikelola oleh masyarakat, pelatihan ketrampilan berbahasa, dan manfaat yang dihasilkan dalam pengembangan desa wisata.

\section{SIMPULAN DAN SARAN}

\section{a. Simpulan}

Berdasarkan hasil penelitian tersebut dapat disimpulkan bahwa Desa Timpag memiliki potensi pariwisata yang dapat dikembangkan menjadi desa wisata berupa potensi alam, potensi budaya, potensi buatan seperti daya tarik wisata Bendungan Telaga Tunjung. Adapun arahan strategi yang dirancang dalam pengembangan desa wisata berbasis masyarakat di Desa Timpag yaitu pengembangan produk wisata berbasis potensi wisata, melibatkan masyarakat lokal dalam pengelolaan desa wisata, penataan atraksi dan fasilitas pariwisata, meningkatkan sistem keamanan berbasis desa adat, membentuk lembaga pariwisata, meningkatakn kemampuan sumber daya manusia dalam bidang pariwisata.

\section{b. Saran}

Berdasarkan simpulan di atas, adapun yang dapat disarankan yaitu diharapkan elemen desa lebih meningkatkan komunikasi dan interaksi dengan Pemerintah ataupun Tim Akademik untuk memperoleh pengetahuan dan pengalaman dalam bidang pariwisata, serta melakukan pendekatan kepada masyarakat lokal guna menumbuhkan peran serta dan kesadaran masyarakat lokal akan pentingnya kepariwisataan berbasis masyarakat yang berkelanjutan. Selain itu, masyarakat juga diharapkan dapat menginventarisasikan dan melestarikan potensi pariwisata yang dimiliki sebagai produk wisata perdesaan sehingga potensi wisata yang dimiliki dapat dijaga dan dilestarikan oleh masyarakat sendiri sebagai tuan rumah .

\section{DAFTAR PUSTAKA}

Antara Bali. 2012. Prospek Pengembangan Wisata di Tabanan Cerah dalam https://bali.antaranews.com/berita/198 78/prospek-pengembangan-wisata-ditabanan-cerah diakses pada Senin, 17 Desember 2018 pukul 20.00 wita.

Bisnis Bali. 2018. Desa Wisata di Tabanan Bertambah dalam https://bisnisbali.com/2018/07/13/des a-wisata-di-tabanan-bertambah/ diakses Senin, 17 Desember 2018 pukul 21.30 wita.

Candranegara, I.Made., Sedana, I.D.G., dan Swatiningsih, K.S. 2018. Pelatihan Manajemen Kelembagaan Desa Sebagai Upaya Pemberian Pelayanan Prima Kepada Masyarakat dan Pengelolaan Potensi Desa di Desa Timpag Tabanan. EJurnal Fakultas Ilmu Sosial dan Ilmu Politik Universitas Warmadewa.

Mahadewi, N.P.K. dan Sudana, I.P. 2017. Model Strategi Pengembangan Desa Wisata Berbasis Masyarakat di Desa Kenderan, Gianyar, Bali. Jurnal Analisis Pariwisata, 
Fakultas Pariwisata Unud Volume 17 No.

1.

Pearce, D. 1995. Tourism A Community Approach $2^{\text {nd }}$ Rangkuti, F. 2005. Analisis SWOT: Teknik Membedah Kasus Bisnis-Orientasi Konsep Perencanaan Strategis Untuk Menghadapi Abad 21. Jakarta: PT. Gramedia Pustaka Utama.

Sanjaya, R.B. 2018. Strategi Pengembangan Pariwisata Berbasis Masyarakat di Desa Kemetul Kabupaten Semarang. Jurnal Master Pariwisata Universitas Kristen Satya Wacana Volume 5 No. 1. 